\title{
High Mast Cell Density Predicts a Favorable Prognosis in Patients with Pancreatic Neuroendocrine Neoplasms
}

\author{
Shengwei Mo Liju Zong Xianlong Chen Xiaoyan Chang Zhaohui Lu \\ Shuangni Yu Jie Chen \\ Department of Pathology, Peking Union Medical College Hospital, Chinese Academy of Medical Sciences \& Peking \\ Union Medical College, Beijing, PR China
}

\section{Keywords}

Mast cell · Pancreatic neuroendocrine neoplasm · Tumorinfiltrating immune cells - Tumor microenvironment .

Prognosis

\begin{abstract}
Introduction: Mast cells are involved in allergic diseases, immune regulation, and tumor microenvironment modulation, with both pro- and anti-tumorigenic functions, and could serve as a prognostic factor in various cancers. However, their potential role in pancreatic neuroendocrine neoplasms (PanNENs) is largely unknown. Here, our aim was to investigate the presence of mast cells in PanNENs and evaluate their association with clinicopathological parameters and other common tumor-infiltrating immune cells. Methods: Tissue microarrays containing PanNEN samples from 187 patients were constructed and stained immunohistochemically for CD117, CD15, CD68, CD3, CD4, and CD8. Immune cells were counted from four high-power fields (HPFs; $\times 400$ ) at maximal concentrations, and the mean counts were calculated per HPF. The cutoff values were set by X-tile. $\boldsymbol{R} \boldsymbol{e}$ sults: The median (interquartile range) counts of CD117 mast cells, $\mathrm{CD}^{+} 5^{+}$neutrophils, $\mathrm{CD}^{+} 8^{+}$macrophages, $\mathrm{CD}^{+} \mathrm{T}$
\end{abstract}

karger@karger.com www.karger.com/nen

Karger $\stackrel{\text { ' }}{5}$

GOPEN ACCESS
(C) 2021 The Author(s)

Published by S. Karger AG, Basel

This is an Open Access article licensed under the Creative Commons Attribution-NonCommercial-4.0 International License (CC BY-NC) (http://www.karger.com/Services/OpenAccessLicense), applicable to the online version of the article only. Usage and distribution for commercial purposes requires written permission. cells, and CD4 ${ }^{+} \mathrm{T}$ cells were 3.5 (2.0-6.0), 3.0 (1.3-6), 3.8 (2.55.8), 13 (8.0-24.0), and 2.0 (1.0-4.0)/HPF, respectively. CD8 ${ }^{+}$ $\mathrm{T}$ cells were not detected. The cutoff values for these immune cells were 1.5/HPF, 6/HPF, 4.8/HPF, 32.5/HPF, and 2/ $\mathrm{HPF}$, respectively. Low mast cell density was correlated with higher grades, noninsulinoma, and advanced stages. Moreover, high mast cell infiltration was associated with elevated $\mathrm{CD}^{+} \mathrm{T}$ cell and CD15+ neutrophil counts. Multivariate analysis revealed that high mast cell density was an independent predictor of prolonged progression-free survival in the entire cohort; in pancreatic neuroendocrine tumors; and in intermediate-grade, noninsulinoma, and advanced stage subgroups. Conclusions: These findings suggest a protective role of mast cells in PanNENs. @ 2021 The Author(s) Published by S. Karger AG, Basel

\section{Introduction}

Pancreatic neuroendocrine neoplasms (PanNENs) are a group of heterogeneous neoplasms arising from neuroendocrine cells of the endocrine pancreas or from precursor cells of the exocrine pancreas [1]. PanNEN is a rare type of neoplasm, the incidence of which was only 0.48
Correspondence to:

Shuangni Yu, yushn@pumch.cn Jie Chen, chenjie@ pumch.cn 
per 100,000 individuals between 2000 and 2012 in the USA. However, an increasing number of patients have been diagnosed with PanNEN over the past 4 decades [2]. The current tumor grading system, as proposed by the World Health Organization (WHO), classifies low-grade pancreatic neuroendocrine tumors (PanNETs) as neoplasms with a Ki-67 index less than $3 \%$ or a mitotic rate less than 2 mitoses $/ 2 \mathrm{~mm}^{2}$, intermediate-grade PanNETs as neoplasms with $\mathrm{Ki}-67$ indices between $3 \%$ and $20 \%$ or mitotic rates between 2 and 20 mitoses $/ 2 \mathrm{~mm}^{2}$, and highgrade PanNENs, including well-differentiated high-grade PanNETs and poorly differentiated pancreatic neuroendocrine carcinomas (PanNECs), as neoplasms with Ki-67 indices greater than $20 \%$ or mitotic rates greater than 20 mitoses $/ 2 \mathrm{~mm}^{2}$ [3]. Even though the WHO grading system is a practicable risk stratification method, the clinical courses of patients with PanNEN are difficult to predict accurately $[4,5]$. Therefore, there remains an urgent need to identify novel prognostic indicators for such patients.

Recent advances in immunotherapy have ignited interest in the exploration of the tumor microenvironmentassociated immune landscape [6-8]. In terms of PanNEN, the number of investigations on tumor-infiltrating immune cells is increasing but remain limited; such studies have explored dendritic cells, neutrophils, macrophages, natural killer cells, $\mathrm{CD}^{+}{ }^{+} \mathrm{T}$ cells, $\mathrm{CD} 45 \mathrm{RO}^{+}$memory T cells, Foxp $3^{+}$regulatory $\mathrm{T}$ cells, $\mathrm{CD} 8^{+}$cytotoxic $\mathrm{T}$ cells, $\mathrm{CD}^{+}$helper $\mathrm{T}$ cells, and $\mathrm{CD} 20^{+} \mathrm{B}$ cells [9-13]. Among these immune cells, only macrophages and neutrophils are potential prognostic biomarkers, although the data remain inconsistent among studies [11-13]. Moreover, the correlation between blood- and tumor-infiltrating immune cells remains unclear [13].

PanNETs associated with hormone oversecretion syndromes (e.g., hyperinsulinemia and Zollinger-Ellison syndrome) are diagnosed as functioning PanNETs, whereas those without any of these clinical syndromes are diagnosed as nonfunctioning PanNETs [14]. Meanwhile, the genetic characteristics and prognoses of insulinomas are distinct from those of nonfunctioning PanNETs and other functioning PanNETs [15]. Tumor-infiltrating immune cells are the basis of immunotherapy [16]. Sufficient targeting immune cells are essential for the administration of immunotherapy. For example, a high tumorinfiltrating lymphocyte density was confirmed to be associated with a higher efficacy of PD-1-/PD-L1-based immunotherapy, which reactivates T-cell-based antitumor immunity [17]. Moreover, ongoing immunotherapeutic strategies targeting chemokine (C-C motif) receptor 2 and colony-stimulating factor 1 receptor $[18,19]$ also require sufficient tumor-associated macrophages. However, it is largely unknown whether there are differences in terms of tumor-infiltrating immune cells in functioning PanNETs versus nonfunctioning PanNETs, as well as in insulinomas versus noninsulinoma, and the prognostic values of immune cells in these subgroups have not yet been demonstrated. Therefore, acquiring a better understanding of the immune infiltrate profiles of these subgroups might help to develop novel and personalized immune cell-targeted therapeutic strategies in a cost-effective manner based on the functionality of PanNETs.

Mast cells, which originate from the bone marrow, are innate immune cells that have a variety of roles in anaphylactic diseases [20]; they also regulate the adaptive immune response [21] and modulate tumorigenesis [22]. In terms of the latter, mast cells have been reported to be either pro-tumorigenic (e.g., in thyroid cancer and primary cutaneous lymphoma) $[23,24]$ or anti-tumorigenic (e.g., in breast and prostate cancers) [25-27]. Soucek et al. $[28,29]$ demonstrated the importance of mast cells in the development and maintenance of pancreatic islet tumors in a transgenic mouse model. However, the prognostic significance of mast cells in patients with PanNEN has not been explored.

To increase our understanding of tumor-infiltrating immune cells in PanNENs, we performed immunohistochemical staining of $\mathrm{CD} 117^{+}$mast cells and $\mathrm{CD}^{+} 8^{+}$macrophages; $\mathrm{CD}_{15}^{+}$neutrophils; and $\mathrm{CD}^{+}, \mathrm{CD}^{+}$, and $\mathrm{CD} 8^{+} \mathrm{T}$ cells to investigate the associations between these common immune cells and clinicopathological parameters, as well as blood immune cells, and to determine their prognostic importance. Our study aimed to determine whether mast cells have prognostic value in patients with PanNENs.

\section{Materials and Methods}

\section{Patients and Specimens}

One hundred and eighty-seven patients with primary PanNENs (PanNETs or PanNECs) who underwent surgical resection between 2004 and 2019 at Peking Union Medical College Hospital (PUMCH) with available samples were included consecutively in this study. The clinicopathological characteristics of the $187 \mathrm{pa}$ tients are summarized in Table 1. All patients' histopathological slides were retrieved, scrutinized, and recategorized histologically by a pathologist (S.N.Y.) if any discordance with the WHO classification was observed [3]. After careful review of hematoxylineosin slides, representative areas of the neoplasm tissues were marked, and the corresponding formalin-fixed paraffin-embedded blocks were sampled for tissue microarray (TMA) construc- 
tion. The diameter of each sample core was $2 \mathrm{~mm}$, as previously described by Zong et al. [30]. To further investigate the distribution of immune cells in PanNENs and the normal pancreas, accessible normal pancreatic tissues from 23 of the 187 patients were also sampled during the TMA construction process. Clinicopathological data such as age, sex, time of surgery, surgical procedure, preoperative and/or postoperative treatments, primary tumor location, tumor size, functional status, number of examined lymph nodes, number of positive lymph nodes, metastasis status, proliferation activity (Ki-67 index and mitotic rate), WHO grade, lymphovascular invasion (LVI), and perineural invasion (PNI) were documented. Routine blood test results (including counts of white blood cells, lymphocytes, monocytes, neutrophils, eosinophils, basophils, and platelets) were obtained within 7 days before surgery. The American Joint Committee on Cancer (AJCC) 8th edition stages were classified according to the data we collected. Survival information was retrospectively extracted from the electronic medical record system and confirmed by telephone interviews. Noninsulinoma was defined as PanNETs excluding insulinoma (including nonfunctioning PanNETs and other functioning PanNETs such as gastrinoma, vasoactive intestinal polypeptide-secreting tumor, and glucagonoma). Our current study was approved by the Institutional Review Board of PUMCH (approval no. S-K1593) and complied with the Helsinki Declaration. The PUMCH Ethics Committee approved this retrospective study and formally waived the requirement for written consent.

\section{Immunohistochemistry}

The immunohistochemical methods used in this study were described previously $[31,32]$. Briefly, immunostaining of CD3, CD4, CD8, CD15, CD68, and CD117 was performed on serial TMA slices $(4 \mu \mathrm{m})$. Details of the antibodies are shown in online supplementary Table S1 (for all online suppl. material, see www. karger.com/doi/10.1159/000521651). Tonsillar tissues treated with primary antibodies were used as positive controls; normal pancreatic tissues were used as internal controls, whereas tissues not treated with isotype-matched antibodies were used as negative controls. All slides were stained automatically using an immunostaining instrument (BOND-III; Leica Biosystems), as per the manufacturer's instructions.

\section{Immunohistochemical Evaluation}

The aforementioned immune markers were scored only when there were sufficient neoplasm tissues, and they were also assessed in normal pancreatic tissues using the same method. In brief, two investigators (S.W.M. and X.L.C.) who were blinded to the patients' clinicopathological characteristics and outcomes (death or progression) evaluated all slides. Any discrepancy was resolved by consensus between these two investigators.

Immune cells were counted manually from four high-power fields (HPFs) of a maximal density at $\times 400$ magnification, and the mean counts of the corresponding cells per HPF were calculated for each sample; this was similar to the method used by Cai et al. [12]. The cutoff values for $\mathrm{CD}^{+}, \mathrm{CD}^{+}$, and $\mathrm{CD} 8^{+} \mathrm{T}$ cells; $\mathrm{CD} 15^{+}$ neutrophils; $\mathrm{CD}^{+} 8^{+}$macrophages; and $\mathrm{CD} 117^{+}$mast cells were determined using X-tile (Yale University, New Haven, CT, USA). Tumor-infiltrating $\mathrm{CD}^{+}, \mathrm{CD}^{+}, \mathrm{CD} 5^{+}$neutrophils; $\mathrm{CD} 68^{+} \mathrm{mac}-$ rophages; and $\mathrm{CD} 117^{+}$mast cells were considered high when the values were equal to or greater than $32.5 / \mathrm{HPF}, 2 / \mathrm{HPF}, 6 / \mathrm{HPF}, 4.8 /$ $\mathrm{HPF}$, and 1.5/HPF, respectively.
Table 1. Clinicopathological characteristics of patients with PanNENs $(N=187)$

\begin{tabular}{|c|c|}
\hline Variables & $\begin{array}{l}\text { Median (IQR) } \\
\text { or } N(\%)\end{array}$ \\
\hline Mean age (IQR), years & $50(41-59)$ \\
\hline \multicolumn{2}{|l|}{ Sex, $n(\%)$} \\
\hline Female & $92(49)$ \\
\hline Male & $95(51)$ \\
\hline \multicolumn{2}{|l|}{ Functional, $n(\%)(N=179)$} \\
\hline No & $87(49)$ \\
\hline$Y_{e s}{ }^{a}$ & $92(51)$ \\
\hline \multicolumn{2}{|l|}{ Functional, $n(\%)(N=179)$} \\
\hline Insulinoma & $77(43)$ \\
\hline Noninsulinoma & $102(57)$ \\
\hline \multicolumn{2}{|l|}{ Primary pancreatic sites, $n$ (\%) } \\
\hline Head/neck & $70(36)$ \\
\hline Body/tail & $115(62)$ \\
\hline Multiple sites & $2(2)$ \\
\hline \multicolumn{2}{|l|}{ Surgical procedure, $n$ (\%) } \\
\hline Distal pancreatectomy & $89(48)$ \\
\hline Pancreaticoduodenectomy & $30(16)$ \\
\hline Enucleation & $53(28)$ \\
\hline Segmental pancreatectomy & $8(4)$ \\
\hline Subtotal/total pancreatectomy & $5(3)$ \\
\hline Unknown & $2(1)$ \\
\hline \multicolumn{2}{|l|}{ Synchronous metastasis, $n$ (\%) } \\
\hline No & $138(74)$ \\
\hline Yes & $49(26)$ \\
\hline \multicolumn{2}{|l|}{$\mathrm{LVI}, n(\%)$} \\
\hline Absent & $171(91.4)$ \\
\hline Present & $16(8.6)$ \\
\hline \multicolumn{2}{|l|}{$\mathrm{PNI}, n(\%)$} \\
\hline Absent & $175(93.6)$ \\
\hline Present & $12(6.4)$ \\
\hline \multicolumn{2}{|l|}{ WHO grade, $n(\%)$} \\
\hline Low & $79(42.3)$ \\
\hline Intermediate & $98(52.4)$ \\
\hline $\mathrm{High}^{\mathrm{b}}$ & $10(5.3)$ \\
\hline \multicolumn{2}{|l|}{ AJCC stage, $n(\%)$} \\
\hline I & $58(31)$ \\
\hline II & $81(43)$ \\
\hline III & $20(11)$ \\
\hline IV & $28(15)$ \\
\hline Median tumor size (IQR), cm & $2.5(1.5-4)$ \\
\hline Median Ki-67 index (IQR), \% & $3(1-5)$ \\
\hline Median mitotic rate (IQR), /10 HPF & $1(1-2)$ \\
\hline Median number of positive nodes (IQR) & $3(2-5.25)$ \\
\hline Median number of resected nodes (IQR) & $2(0-8)$ \\
\hline Median number of WBCs (IQR), $\times 10^{9} / \mathrm{L}$ & $5.47(4.48-7.14)$ \\
\hline Median number of lymphocytes (IQR), $\times 10^{9} / \mathrm{L}$ & $1.67(1.33-2.02)$ \\
\hline Median number of monocytes (IQR), $\times 10^{9} / \mathrm{L}$ & $0.33(0.25-0.40)$ \\
\hline Median number of neutrophils (IQR), $\times 10^{9} / \mathrm{L}$ & $3.24(2.30-4.22)$ \\
\hline Median number of eosinophils (IQR), $\times 10^{9} / \mathrm{L}$ & $0.11(0.07-0.17)$ \\
\hline Median number of basophils (IQR), $\times 10^{9} / \mathrm{L}$ & $0.02(0.02-0.03)$ \\
\hline Median number of platelets (IQR), $\times 10^{9} / \mathrm{L}$ & $220(180.50-256.75)$ \\
\hline
\end{tabular}

a Including 77 insulinomas, 7 vasoactive intestinal polypeptide-secreting tumors, 3 gastrinomas, 3 glucagonomas, and 2 adrenocorticotropic-hormone-producing tumors. ${ }^{\text {b }}$ Including 2 neuroendocrine grade 3 tumors and 8 neuroendocrine carcinomas. 


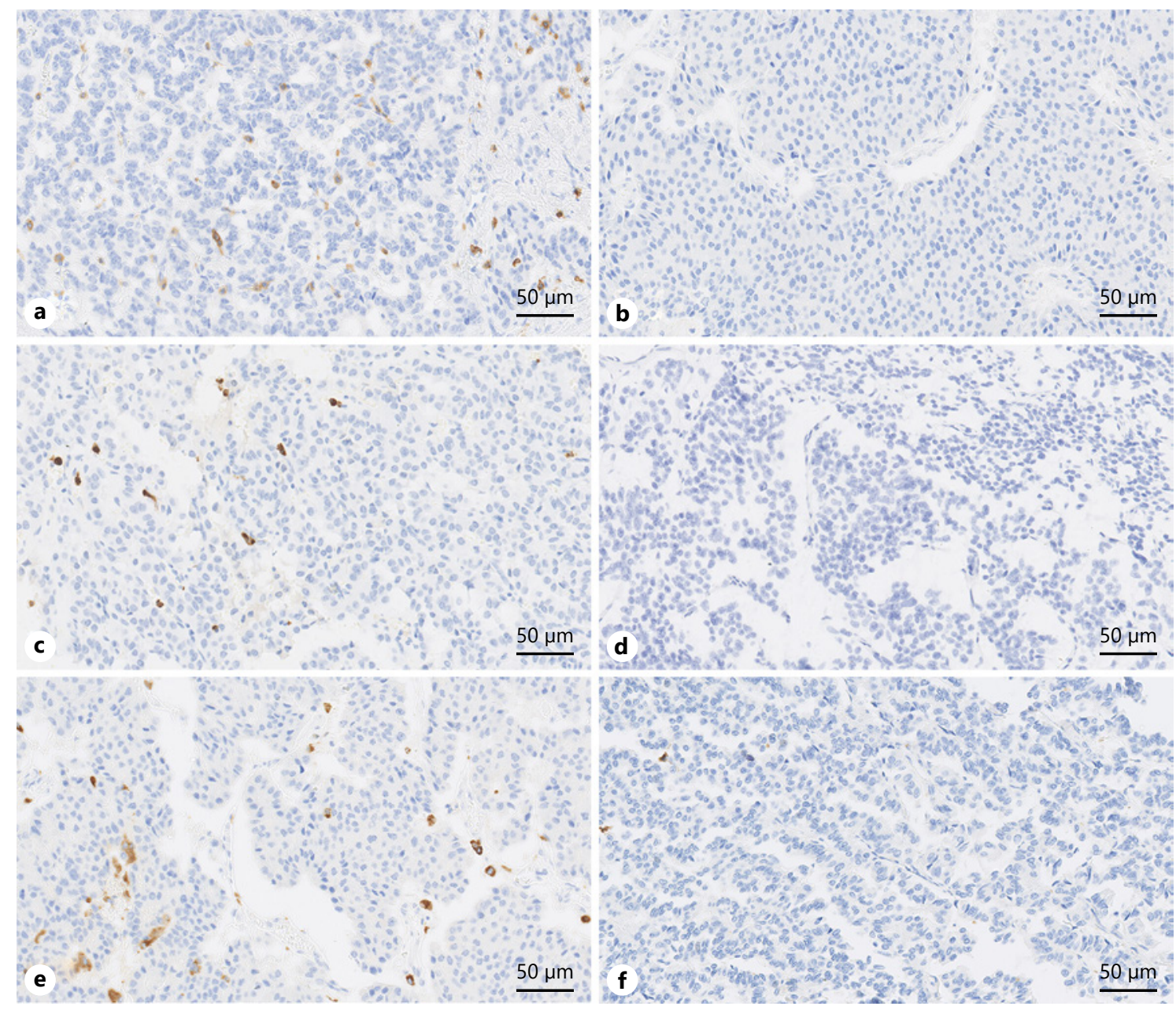

Fig. 1. Tumor-infiltrating innate immune cells in resected primary PanNEN formalin-fixed and paraffin-embedded samples using immunohistochemically stained TMAs. High $(\geq 1.5 / \mathrm{HPF}) \mathrm{CD} 117^{+}$ mast cell density in a low-grade nonfunctioning PanNET sample (a); low $(<1.5 / \mathrm{HPF}) \mathrm{CD} 117^{+}$mast cell density in a high-grade insulinoma sample (b); (c) high ( $\geq 6 / \mathrm{HPF}) \mathrm{CD} 15^{+}$neutrophil density in

\section{Statistical Analysis}

Continuous and categorical variables are presented as medians with interquartile ranges (IQRs; first quartiles-third quartiles) and frequencies with percentages, respectively. Relative risk was determined by calculating the hazard ratio and corresponding $95 \%$ confidence interval. The Mann-Whitney U-test or Kruskal-Wallis test was undertaken for comparisons of quantitative variables among groups, whereas Pearson's $\chi^{2}$ or Fisher's exact test was performed to compare qualitative variables. Correlations between quantitative variables were determined using Spearman's $\rho$.

Progression-free survival (PFS) and overall survival (OS) were calculated from the date of surgery to the date of progression or death from any cause, respectively, or to the date of the last follow-up. The final data collection date was December 29, 2020. Kaplan-Meier plots were generated using Prism 8.0.2 software (GraphPad Software Inc., San Diego, CA, USA). Univariate an intermediate-grade insulinoma sample (c); low $(<6 / \mathrm{HPF}) \mathrm{CD} 15^{+}$ neutrophil density in an intermediate-grade insulinoma sample (d); high $(\geq 4.8 / \mathrm{HPF}) \mathrm{CD}^{+} 8^{+}$macrophage density in a high-grade insulinoma sample (e); and low (<4.8/HPF) $\mathrm{CD} 68^{+}$macrophage density in a low-grade vasoactive intestinal polypeptide-secreting tumor sample (original magnifications, $\times 400$; scale bar, $50 \mu \mathrm{m})(\mathbf{f})$.

and multivariate analyses were performed using Cox proportional hazards regression (forward: LR method). After excluding 7 patients who were lost to follow-up and one who died of postoperative infection and acute hepatic failure, 179 patients (96\%) were subjected to survival analysis. No significant difference in clinicopathological data and immune infiltrates was observed between the included and excluded patients. To investigate the prognostic value of tumor-infiltrating immune cells in different clinically relevant subgroups, patients included in survival analysis were divided into different subgroups. The flow diagram for subgrouping and sample sizes of each subgroup are summarized in online supplementary Figure S1.

A $p$ value less than 0.05 was considered statistically significant, and all statistical tests used were two-tailed. Data were analyzed using Statistical Product and Service Solutions statistical software for Windows, version 21.0 (IBM Corp., Armonk, NY, USA). 

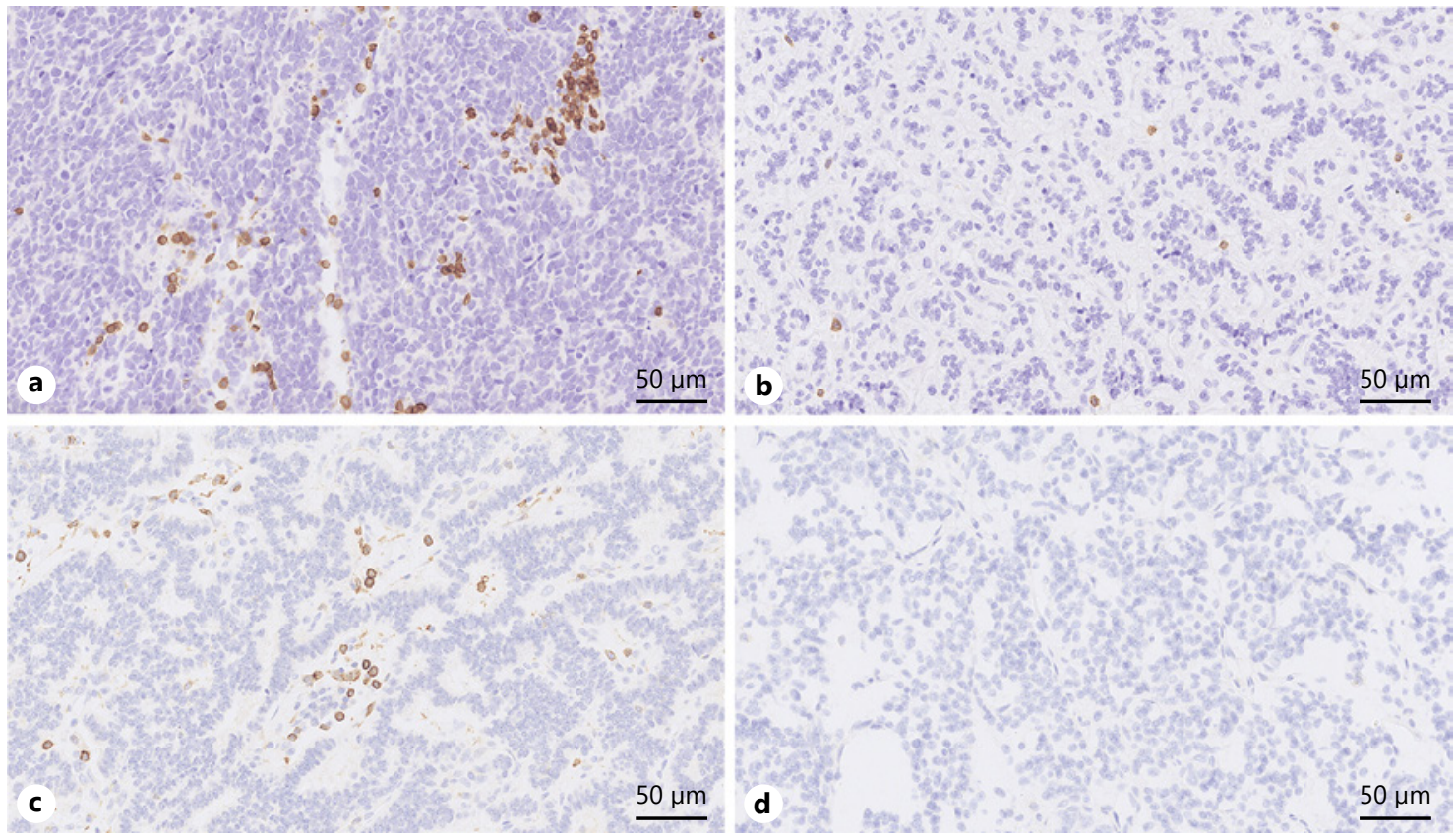

Fig. 2. Tumor-infiltrating $\mathrm{T}$ lymphocytes in resected primary PanNEN formalin-fixed and paraffin-embedded samples using immunohistochemically stained TMAs. High $(\geq 32.5 / \mathrm{HPF}) \mathrm{CD}^{+}$ T-cell density in a high-grade PanNEC sample (a); low ( $<32.5 /$ $\mathrm{HPF}$ ) $\mathrm{CD}^{+}$T-cell density in an intermediate-grade nonfunc- tioning PanNET sample (b); high $(\geq 2 / \mathrm{HPF}) \mathrm{CD} 4^{+} \mathrm{T}$-cell density in an intermediate-grade nonfunctioning PanNET (c); and low $(<2 / \mathrm{HPF}) \mathrm{CD}^{+} \mathrm{T}$-cell density in an intermediate-grade nonfunctioning PanNET (original magnifications, $\times 400$; scale bar, 50 $\mu \mathrm{m})(\mathbf{d})$.
Table 2. Distribution of immune cells in PanNENs and in normal pancreatic tissues

\begin{tabular}{llll}
\hline Cell type & $\begin{array}{l}\text { PanNEN } \\
\text { (median [IQR]/HPF) }\end{array}$ & $\begin{array}{l}\text { Normal pancreas } \\
\text { (median [IQR]/HPF) }\end{array}$ & $p$ value \\
\hline CD117 $7^{+}$mast cell & $3.5(2-6)$ & $2.3(1-4.8)$ & $\mathbf{0 . 0 3 5}$ \\
CD15 neutrophil & $3(1.3-6)$ & $2.5(1.3-3.8)$ & 0.274 \\
CD68 ${ }^{+}$macrophage & $3.8(2.5-5.8)$ & $2.6(1-4.4)$ & $\mathbf{0 . 0 3 6}$ \\
CD3 $^{+}$T cell & $13(8-24)$ & $13(5-23.8)$ & 0.661 \\
CD4 $^{+}$T cell & $2(1-4)$ & $1.8(0.8-4)$ & 0.623 \\
\hline
\end{tabular}

\section{Results}

\section{Tumor-Infiltrating Immune Cells in PanNENs}

Immune cell infiltration was detected in all neoplasm samples, and representative immunohistochemical staining images of $\mathrm{CD} 117^{+}$mast cells, $\mathrm{CD}^{+} 8^{+}$macrophages, $\mathrm{CD}_{15}{ }^{+}$neutrophils, $\mathrm{CD}^{+}$, and $\mathrm{CD}^{+} \mathrm{T}$ cells are presented (shown in Fig. 1,2). The median counts of these cells in PanNENs and normal pancreatic tissues are shown in Table 2 and online supplementary Figure S2. T cells labeled by CD3 were the most abundant immune cells in PanNENs, whereas $\mathrm{CD} 8^{+} \mathrm{T}$ cells were not observed in our cohort of samples. The median count of mast cells was 3.5/HPF (IQR: 2.0-6.0/HPF), and high ( $\geq 1.5 / \mathrm{HPF}$ ) mast cell infiltration was observed in $155(83 \%)$ of the samples. Furthermore, a high density of $\mathrm{CD} 117^{+}$mast cells was correlated with high numbers of $\mathrm{CD}^{+} \mathrm{T}$ cells (Spearman's $\rho=0.187, p=0.010$ ) and CD15 ${ }^{+}$neutrophils (Spearman's $\rho=0.184, p=0.012$ ). Details of the associations between these immune cells are shown in online supplementary Table S2; Figure S3.

\section{Associations between Immune Infiltrates and} Clinicopathological Characteristics in PanNEN

We further compared the numbers of $\mathrm{CD} 117^{+}$mast cells, $\mathrm{CD} 68^{+}$macrophages, $\mathrm{CD} 15^{+}$neutrophils, and $\mathrm{CD} 3^{+}$ and $\mathrm{CD}_{4}^{+} \mathrm{T}$ cells based on different WHO grades, PanNET versus PanNEC, the absence or presence of LVI and 
Table 3. Univariate analysis of factors potentially associated with PFS

\begin{tabular}{|c|c|c|}
\hline & $\mathrm{HR}(95 \% \mathrm{Cl})$ & $p$ value \\
\hline \multicolumn{3}{|l|}{ WHO grade } \\
\hline Low-grade & 1 & \multirow[t]{3}{*}{$<0.001$} \\
\hline Intermediate-grade & $6.29(2.43-16.28)$ & \\
\hline High-grade & 29.32 (8.64-99.47) & \\
\hline \multicolumn{3}{|l|}{ Ki-67 index } \\
\hline$<3 \%$ & 1 & \multirow[t]{2}{*}{$<0.001$} \\
\hline$\geq 3 \%$ & 7.30 (3.05-17.46) & \\
\hline \multicolumn{3}{|l|}{ Mitotic rate } \\
\hline$<2 / 10 \mathrm{HPF}$ & 1 & \multirow[t]{2}{*}{$<0.001$} \\
\hline$\geq 2 / 10 \mathrm{HPF}$ & $6.21(2.74-14.06)$ & \\
\hline \multicolumn{3}{|l|}{ LVI } \\
\hline Absent & 1 & \multirow[t]{2}{*}{$<0.001$} \\
\hline Present & $4.37(2.08-9.18)$ & \\
\hline \multicolumn{3}{|l|}{ PNI } \\
\hline Absent & 1 & \multirow[t]{2}{*}{0.022} \\
\hline Present & 3.01 (1.18-7.69) & \\
\hline \multicolumn{3}{|l|}{ Tumor stage } \\
\hline $\mathrm{T} 1 / \mathrm{T} 2$ & 1 & \multirow[t]{2}{*}{$<0.001$} \\
\hline $\mathrm{T} 3 / \mathrm{T} 4$ & $4.28(2.33-7.88)$ & \\
\hline \multicolumn{3}{|l|}{ Lymph node metastasis } \\
\hline Absent & 1 & \multirow[t]{2}{*}{$<0.001$} \\
\hline Present & $5.85(3.18-10.73)$ & \\
\hline \multicolumn{3}{|l|}{ Distant metastasis } \\
\hline Absent & 1 & \multirow[t]{2}{*}{$<0.001$} \\
\hline Present & $16.01(8.47-30.27)$ & \\
\hline \multicolumn{3}{|l|}{ AJCC stage } \\
\hline I/II & 1 & \multirow[t]{2}{*}{$<0.001$} \\
\hline III/IV & 17.19 (8.17-36.14) & \\
\hline \multicolumn{3}{|l|}{$\mathrm{CD}_{117^{+}}$mast cell } \\
\hline$<1.5 / \mathrm{HPF}$ & 1 & \multirow[t]{2}{*}{0.003} \\
\hline$\geq 1.5 / \mathrm{HPF}$ & $0.36(0.18-0.72)$ & \\
\hline \multicolumn{3}{|l|}{$\mathrm{CD}^{+} 5^{+}$neutrophil } \\
\hline$<6 / \mathrm{HPF}$ & 1 & \multirow[t]{2}{*}{0.095} \\
\hline$\geq 6 / \mathrm{HPF}$ & $0.37(0.11-1.19)$ & \\
\hline \multicolumn{3}{|l|}{$\mathrm{CD}^{-} 8^{+}$macrophage } \\
\hline$<4.8 / \mathrm{HPF}$ & 1 & \multirow[t]{2}{*}{0.061} \\
\hline$\geq 4.8 / \mathrm{HPF}$ & $1.79(0.98-3.27)$ & \\
\hline \multicolumn{3}{|l|}{$\mathrm{CD}^{+} \mathrm{T}$ cell } \\
\hline$<32.5 / \mathrm{HPF}$ & 1 & \multirow[t]{2}{*}{$<0.001$} \\
\hline$\geq 32.5 / \mathrm{HPF}$ & $2.74(1.42-5.27)$ & \\
\hline $\mathrm{CD}^{+} \mathrm{T}$ cell & & \\
\hline$<2 / \mathrm{HPF}$ & 1 & 0.897 \\
\hline$\geq 2 / \mathrm{HPF}$ & $0.96(0.51-1.81)$ & \\
\hline
\end{tabular}

$\mathrm{HR}$, hazard ratio; $\mathrm{Cl}$, confidence interval.

PNI, different functional statuses, T1/2 versus T3/4, the absence or presence of lymph node metastasis and distant metastasis, and AJCC stage I/II versus III/IV subgroups, and the results are summarized in online supplementary Figure S4. The number of mast cells in low-grade PanNENs (4.5, IQR: 2.25-6.75) was higher than that in inter- mediate- or high-grade PanNENs (intermediate-grade: 3 , IQR: $1.75-5, p=0.021$; high-grade: 2.63 , IQR: $0.25-5.25$, $p=0.040$; online suppl. Fig. S4a). In contrast, the number of macrophages in low-grade PanNENs (3.25, IQR: 2.254.75) was lower than that in intermediate- or high-grade PanNENs (intermediate-grade: 4.25 , IQR: $2.5-6.5, p=$ 0.012; high-grade: 5.88 , IQR: $4.38-12.75, p=0.006$; online suppl. Fig. S4a), whereas patients with PanNEC had significantly higher counts of $\mathrm{CD}^{+} \mathrm{T}$ cells (38.63 vs. 13/ $\mathrm{HPF}, p=0.004)$ when compared with those in patients with PanNET (online suppl. Fig. S4b).

Patients with LVI exhibited a higher concentration of $\mathrm{CD}^{+} \mathrm{T}$ cells $(23.88$ vs. $12.25 / \mathrm{HPF}, p=0.010)$ and $\mathrm{CD} 4^{+} \mathrm{T}$ cells ( 4 vs. $2 / \mathrm{HPF}, p=0.003$ ) than those without LVI (online suppl. Fig. S4c). Similarly, a higher concentration of $\mathrm{CD}^{+} \mathrm{T}$ cells $(21.88$ vs. $12.5 / \mathrm{HPF}, p=0.021)$ and $\mathrm{CD} 4^{+} \mathrm{T}$ cells ( 4 vs. $2 / \mathrm{HPF}, p=0.016$ ) was observed in patients with PNI than in those without PNI (online suppl. Fig. S4d).

No significant difference between functioning PanNETs and nonfunctioning PanNETs was detected (online suppl. Fig. S4e), but higher numbers of mast cells ( 4.25 vs. 3.13/ HPF, $p=0.042$ ) and neutrophils (3.5 vs. $2.5 / \mathrm{HPF}, p=0.016$ ) were observed in the insulinoma subgroup but not in the noninsulinoma subgroup (online suppl. Fig. S4f).

There were no statistically significant differences between different tumor stages or lymph node metastasis statuses (online suppl. Fig. S4g, h). Of note, patients with distant metastases had lower mast cell infiltration than those without distant metastases ( 2.25 vs. $3.75 / \mathrm{HPF}, p=$ 0.017) (online suppl. Fig. S4i), and patients with advanced-stage disease (AJCC stage III/IV) showed lower counts of mast cells ( 2.38 vs. $4 / \mathrm{HPF}, p=0.006)$ and neutrophils ( 2.13 vs. $3.25 / \mathrm{HPF}, p=0.008)$ than those with AJCC stage I/II disease; however, patients with AJCC stage III/IV disease had higher macrophage infiltration (4.75 vs. $3.5 / \mathrm{HPF}, p=0.042$; online suppl. Fig. S4j).

Additionally, elevated numbers of $\mathrm{CD}^{+} \mathrm{T}$ cells were associated with a high blood lymphocyte count in PanNEN tissues. Details of the associations between blood cell counts and immune infiltrates are shown in online supplementary Table S3; Figure S5.

\section{Survival Analyses of Patients with PanNEN}

The 5-year OS and PFS rates were $94 \%$ and $68 \%$. The median follow-up time was 44 months (IQR: 26-66 months), and the median 5-year PFS was 40 months (IQR: 19-52 months). Moreover, none of the examined variables were found to significantly influence OS. Univariate analysis data for PFS are presented in Table 3. Kaplan-Meier curves with patients categorized by clinico- 

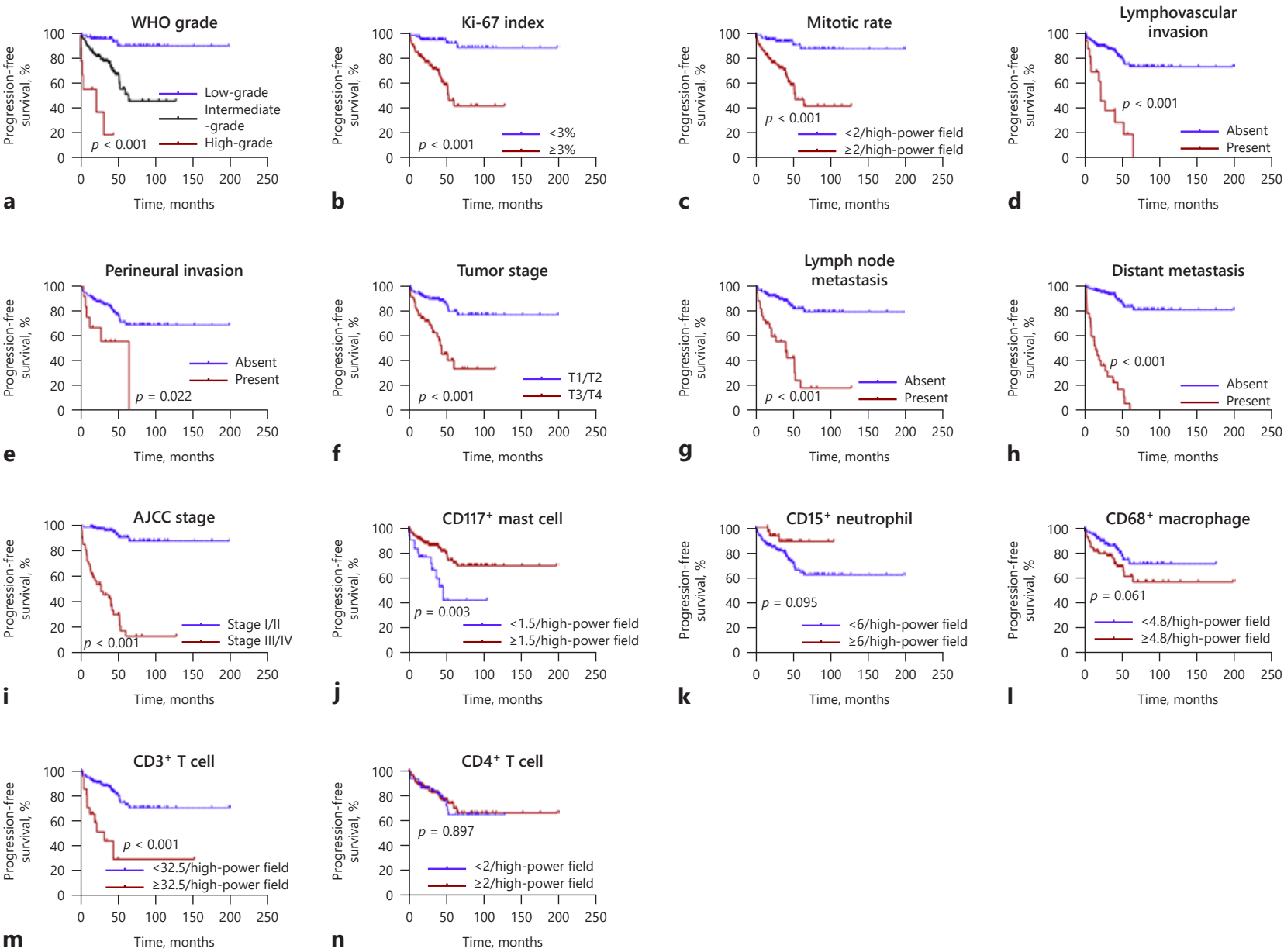

Fig. 3. Kaplan-Meier curves of the PFS of patients with PanNENs $(N=179)$ categorized by clinicopathological parameters and tumor-infiltrating immune cell counts. PFS of patients based on WHO grade (low-grade vs. intermediate-grade vs. high-grade) (a); Ki-67 index ( $<3 \%$ vs. $\geq 3 \%$ ) (b); mitotic rate ( $<2 / \mathrm{HPF}$ vs. $\geq 2 / \mathrm{HPF})$ (c); LVI (absent vs. present) (d); PNI (absent vs. present) (e); tumor stage (T1/T2 vs. T3/T4) (f); lymph node metastasis (absent vs. present) (g); distant metastasis (absent vs. present) (h); AJCC stage (stage I/II vs. III/IV) (i); CD $117^{+}$mast cell density ( $<1.5 / \mathrm{HPF}$ vs. $\geq 1.5 / \mathrm{HPF}$ ) (j); CD $15^{+}$neutrophil density ( $<6 / \mathrm{HPF}$ vs. $\geq 6 / \mathrm{HPF}$ ) (k); $\mathrm{CD}^{+} 8^{+}$macrophage density $(<4.8 / \mathrm{HPF}$ vs. $\geq 4.8 / \mathrm{HPF})$ (I); $\mathrm{CD}^{+}$T-cell density $(<32.5 / \mathrm{HPF}$ vs. $\geq 32.5 / \mathrm{HPF})(\mathbf{m})$; and $\mathrm{CD} 4^{+}$ T-cell density ( $<2 / \mathrm{HPF}$ vs. $\geq 2 / \mathrm{HPF})$ (n). pathological parameters and tumor-infiltrating immune cell counts are shown in Figure 3. No significant association was found between PFS and any of $\mathrm{CD} 4^{+} \mathrm{T}$ cells, $\mathrm{CD}_{15}{ }^{+}$neutrophils, and $\mathrm{CD} 68^{+}$macrophages, although a low number of neutrophils and high macrophage counts showed a trend toward an association with poorer survival ( $p=0.095$ and 0.061 , respectively). Meanwhile, patients with a high density of mast cells and low $\mathrm{CD}^{+} \mathrm{T}$ cells had longer PFS.

According to multivariate Cox regression analysis, WHO grade, LVI, AJCC stage, and mast cell counts were independent predicators of PFS (Table 4). We further conducted subgroup analyses to investigate the prognostic value of $\mathrm{CD} 117^{+}$mast cells, as well as other immune cells, in the clinically relevant subgroups using multivariate Cox regression analysis. Results of mast cell density stratified by clinically important subgroups are shown in online supplementary Table S4; Figure S6. Intriguingly, we found that high mast cell density remained an independent protective indicator in intermediate-grade, PanNET, noninsulinoma, and AJCC stage III/IV subgroups, whereas other immune cells, except $\mathrm{CD}^{+} \mathrm{T}$ cells (hazard 
Table 4. Multivariate analysis of factors potentially associated with PFS

\begin{tabular}{|c|c|c|}
\hline & $\mathrm{HR}(95 \% \mathrm{Cl})$ & $p$ value \\
\hline WHO grade & & $<0.001$ \\
\hline Low-grade & 1 & \\
\hline Intermediate-grade & $2.64(0.98-7.11)$ & 0.055 \\
\hline High-grade & $20.42(5.73-72.80)$ & $<0.001$ \\
\hline \multicolumn{3}{|l|}{ PNI } \\
\hline Absent & 1 & 0.003 \\
\hline Present & $4.84(1.71-13.68)$ & \\
\hline \multicolumn{3}{|l|}{ AJCC stage } \\
\hline $\mathrm{I} / \mathrm{II}$ & 1 & $<0.001$ \\
\hline III/IV & $15.28(6.93-33.66)$ & \\
\hline \multicolumn{3}{|l|}{ CD $117^{+}$mast cell } \\
\hline$<1.5 / \mathrm{HPF}$ & 1 & $<0.001$ \\
\hline$\geq 1.5 / \mathrm{HPF}$ & $0.26(0.13-0.55)$ & \\
\hline
\end{tabular}

$\mathrm{HR}$, hazard ratio; $\mathrm{Cl}$, confidence interval.

ratio: $2.76,95 \%$ confidence interval: $1.01-7.52, p=0.048$ ), were not found to have independent prognostic significance in any of the subgroups, based on multivariate Cox regression analysis of patients with nonfunctioning PanNET (online suppl. Fig. S7).

\section{Discussion/Conclusion}

Although recent studies of PanNEN based on both animal models and human tissues have shown that tumorinfiltrating immune cells (e.g., tumor-associated macrophages, neutrophils, and $\mathrm{CD}^{+}$programmed cell death protein $1^{+} \mathrm{T}$ cells) might play an important role in the pathogenesis of this disease and serve as prognostic biomarkers [10-13], the limitations of these studies are obvious. Most of the previous studies either investigated tumor-infiltrating immune cells in a group (e.g., nonfunctioning PanNETs) with a small number of patients or included heterogeneous neuroendocrine neoplasms from other sites, which potentially limits their clinical application. Therefore, to improve our understanding of the role of tumor-infiltrating immune cells in PanNENs, a comprehensive analysis of six common immune cells in 187 patients with PanNEN was conducted.

Intriguingly, we found that mast cells were the most informative prognostic indicator among these six immune cells, independent of the WHO grade and AJCC stage. Accumulating evidence indicates that the prognostic significance and the plastic pro- or anti-tumorigenic function of mast cells are tumor-dependent [22-27]. Soucek et al. [28, 29] first noted the importance of mast cells in a $p I n s-m y c E R^{T A M} ; R I P 7-b c l-x_{L}$ pancreatic islet tumor model, where inhibiting mast cell degranulation or creating a mast cell-deficient mouse model induced hypoxia and apoptosis in tumor and endothelial cells, indicating a pro-tumorigenic role of mast cells. Although Soucek et al. [28] confirmed the presence of $\mathrm{CD} 117^{+}$mast cells in human insulinomas, the prognostic significance of these cells with respect to PanNEN was still largely unclear. Furthermore, $\mathrm{CD} 117^{+}$mast cells were not detected in the tumor islets of $p I n s-m y c E R^{T A M} ; R I P 7-b c l-x_{L}$ transgenic mice [29]. Moreoever, the authors acknowledged that the degranulation inhibitors and mast cell deficiency in their transgenic animals might have produced off-target effects on other cells [28, 29]. In contrast, we highlighted the potentially anti-tumorigenic role of mast cells in PanNENs, which could be explained as follows: (i) endogenous peroxidase and reactive oxidative species released by mast cells might be tumoricidal $[33,34]$; (ii) cytokines (such as tumor necrosis factor) that are required for mast cell-dependent T-cell activation can be produced by mast cells $[35,36]$; (iii) mast cells can enhance the migration, maturation, antigen uptake, and presentation capabilities of dendritic cells via the secretion of histamine, mast cell-derived exosomes, and granules, as well as the transmission of antigen-IgE-FceRI complexes [21]; and (iv) mast cells can serve as antigenpresenting cells and further activate cytotoxic $\mathrm{CD}^{+} \mathrm{T}$ cells [37]. Another possible explanation for this prognostic importance of $\mathrm{CD} 117^{+}$mast cells is that the correlation between a high density of $\mathrm{CD} 117^{+}$mast cells and prolonged PFS reflects the biological behavior of PanNEN rather than an active antitumor role for them. There were significantly more mast cells in low-grade PanNENs than in their intermediate- or high-grade counterparts. If the number of mast cells was relatively constant, then, in fastgrowing intermediate- or high-grade PanNENs, the density of mast cells could be "diluted", and the WHO grade could be a confounder. Therefore, we conducted multivariate Cox regression analysis and stratified (subgroup) analyses to control for confounding factors. Moreover, the results of our study based on these analyses did not support such hypotheses based on the following: (i) mast cell density was a prognostic indicator independent of WHO grade in multivariate Cox regression analysis and (ii) mast cell density remained an independent prognostic factor in the intermediate-grade PanNENs subgroup, and high mast cell density tended to be associated with longer PFS in low- and high-grade PanNEN subgroups. 
Additionally, we observed weak but significant correlations between mast cells and $\mathrm{CD}^{+}{ }^{+} \mathrm{T}$ cells, as well as $\mathrm{CD}_{15}{ }^{+}$neutrophils; these might be attributable to tumor necrosis factor, CCL3/4 (which are capable of recruiting T cells), CXCL1/2 (which are responsible for neutrophil recruitment), and OX40 ligand (which can promote Tcell proliferation via OX40-OX40 ligand interactions) [38-41]. Such correlations and interactions could partially explain why $\mathrm{CD}^{+} \mathrm{T}$ cells, $\mathrm{CD} 4^{+} \mathrm{T}$ cells, and $\mathrm{CD} 15^{+}$ neutrophils were not found to be an independent prognostic indicator in the current study. Hence, the complex interactions between mast cells and other immune cells in PanNENs still require additional investigation.

We also analyzed $\mathrm{CD}^{+}, \mathrm{CD}^{+}$, and $\mathrm{CD}^{+}{ }^{+} \mathrm{T}$ cells, as well as $\mathrm{CD}_{15}{ }^{+}$neutrophils and $\mathrm{CD} 68^{+}$macrophages, in PanNENs. $\mathrm{CD}^{+} \mathrm{T}$ cells were significantly more abundant in PanNEC and were associated with a shorter PFS; this finding was consistent with those of Takahashi et al. [10] and Milione et al. [42]. Although no statistically significant associations between other infiltrating immune cell counts and prognosis were found, high macrophage density approached significance and was more prevalent in patients with adverse prognoses in our cohort; this was consistent with previous studies of patients with PanNETs $[11,12]$. The discrepancy between our study and previous investigations of tumor-infiltrating immune cells in patients with PanNET might be explained by the differences between cohorts (i.e., PanNENs vs. PanNETs vs. only nonfunctioning PanNETs), as well as the different evaluation methods used. Moreover, mast cells were not investigated in these studies. Therefore, full-scale investigations into tumor-infiltrating immune cells in PanNENs remain an urgent need.

This study had some limitations. First, given its retrospective nature and the lack of a validation cohort, in addition to the fact that patients were from a single center, the generalizability of our results might be limited. However, we were still able to investigate common tumor-infiltrating immune cells in a rare type of neoplasm (i.e., PanNEN), with a relatively large sample size. Second, to reduce the influence of intra-tumoral heterogeneity on our results as much as possible by using TMAs that were $2 \mathrm{~mm}$ in diameter were constructed to include greater areas, and immune cells were counted from four HPFs. Third, the mechanisms underlining the interactions between PanNEN and immune cells were not examined, owing to the paucity of human PanNEN cell lines and the difficulty of establishing PanNEN organoids [43].

In summary, our comprehensive analysis of common tumor-infiltrating immune cells in patients with PanNEN underscored the potentially protective role of mast

Mast Cells in Pancreatic Neuroendocrine Neoplasms cells. Low mast cell counts can potentially be used to identify patients with PanNEN who have a high risk of progression.

\section{Acknowledgment}

We acknowledge the efforts of the staff of the Medical Record Room in record retrieval.

\section{Statement of Ethics}

Our study was conducted in accordance with the guidelines set forth by the Declaration of Helsinki and was approved by the Institutional Review Board of PUMCH (approval no. S-K1593). Given the retrospective study design and analysis of clinical data, the requirement for written consent was formally waived by the PUMCH Ethics Committee.

\section{Conflict of Interest Statement}

The authors declare that they have no conflicts of interest.

\section{Funding Sources}

This work was supported by grants from the Chinese Academy of Medical Sciences Initiative for Innovative Medicine (CAMS2016-I2M-1-001), National Scientific Data Sharing Platform for Population and Health (NCMI-YF01N-201906), and the National Natural Science Foundation of China (Nos. 81472326, 81672648 and 82001664). The funders of the study had no role in the design of the study; the collection, analysis, and interpretation of data; or in writing the manuscript.

\section{Author Contributions}

Jie Chen and Shuangni Yu made substantial contributions to the conception, design, and critical revision of the manuscript. Shengwei Mo, Liju Zong, and Xianlong Chen developed the methodology for immunostaining and evaluated the immunohistochemical data. Shengwei Mo, Liju Zong, Xianlong Chen, Shuangni Yu, Xiaoyan Chang, Zhaohui Lu, and Shuangni Yu made substantial contributions to sample collection, as well as TMA construction. Shengwei Mo made substantial contributions to data acquisition. Shengwei Mo and Xianlong Chen interpreted the data, performed statistical analysis, and drafted the manuscript. All the authors read and approved the final manuscript.

\section{Data Availability Statement}

The data used and/or analyzed during the current study are available from the corresponding author upon reasonable request. 


\section{References}

1 Vortmeyer AO, Huang S, Lubensky I, Zhuang Z. Non-islet origin of pancreatic islet cell tumors. J Clin Endocrinol Metab. 2004 Apr; 89(4):1934-8.

2 Dasari A, Shen C, Halperin D, Zhao B, Zhou $\mathrm{S}, \mathrm{Xu} \mathrm{Y}$, et al. Trends in the incidence, prevalence, and survival outcomes in patients with neuroendocrine tumors in the United States. JAMA Oncol. 2017 Oct;3(10):1335-42.

3 Nagtegaal ID, Odze RD, Klimstra D, Paradis V, Rugge M, Schirmacher P, et al. The 2019 WHO classification of tumours of the digestive system. Histopathology. 2020 Jan;76(2): 182-8.

4 Jensen RT, Bodei L, Capdevila J, Couvelard A, Falconi M, Glasberg S, et al. Unmet needs in functional and nonfunctional pancreatic neuroendocrine neoplasms. Neuroendocrinology. 2019;108(1):26-36.

5 Young K, Lawlor RT, Ragulan C, Patil Y, Mafficini A, Bersani S, et al. Immune landscape, evolution, hypoxia-mediated viral mimicry pathways and therapeutic potential in molecular subtypes of pancreatic neuroendocrine tumours. Gut. 2021;70(10):1904-13.

6 Pérez-Romero K, Rodríguez RM, Amedei A, Barceló-Coblijn G, Lopez DH. Immune landscape in tumor microenvironment: implications for biomarker development and immunotherapy. Int J Mol Sci. 2020 Aug;21(15): 5521.

7 Boussiotis VA. Molecular and biochemical aspects of the PD-1 checkpoint pathway. N Engl J Med. 2016 Nov;375(18):1767-78.

8 Reck M, Rodríguez-Abreu D, Robinson AG, Hui R, Csőszi T, Fülöp A, et al. Pembrolizumab versus chemotherapy for PD-L1-positive non-small-cell lung cancer. N Engl J Med. 2016 Nov;375(19):1823-33.

9 Ryschich E, Autschbach F, Eisold S, Klar E, Buchler MW, Schmidt J. Expression of HLA class I/II antigens and T cell immune response in human neuroendocrine tumors of the pancreas. Tissue Antigens. 2003 Jul;62(1):48-54.

10 Takahashi D, Kojima M, Suzuki T, Sugimoto M, Kobayashi S, Takahashi S, et al. Profiling the tumour immune microenvironment in pancreatic neuroendocrine neoplasms with multispectral imaging indicates distinct subpopulation characteristics concordant with WHO 2017 classification. Sci Rep. 2018 Sep; 8(1):13166.

11 Wei IH, Harmon CM, Arcerito M, Cheng DF, Minter RM, Simeone DM. Tumor-associated macrophages are a useful biomarker to predict recurrence after surgical resection of nonfunctional pancreatic neuroendocrine tumors. Ann Surg. 2014 Dec;260(6): 1088-94.

12 Cai L, Michelakos T, Deshpande V, Arora KS, Yamada T, Ting DT, et al. Role of tumor-associated macrophages in the clinical course of pancreatic neuroendocrine tumors (PanNETs). Clin Cancer Res. 2019 Apr;25(8): 2644-55.
13 Zhang WH, Wang WQ, Gao HL, Xu SS, Li S, Li TJ, et al. Tumor-infiltrating neutrophils predict poor survival of non-functional pancreatic neuroendocrine tumor. J Clin Endocrinol Metab. 2020 Jul;105(7):dgaa196.

14 Falconi M, Eriksson B, Kaltsas G, Bartsch DK, Capdevila J, Caplin M, et al. ENETS consensus guidelines update for the management of patients with functional pancreatic neuroendocrine tumors and non-functional pancreatic neuroendocrine tumors. Neuroendocrinology. 2016;103(2):153-71.

15 Hong X, Qiao S, Li F, Wang W, Jiang R, Wu $\mathrm{H}$, et al. Whole-genome sequencing reveals distinct genetic bases for insulinomas and non-functional pancreatic neuroendocrine tumours: leading to a new classification system. Gut. 2020 May;69(5):877-87.

16 Zhang $\mathrm{Y}$, Zhang Z. The history and advances in cancer immunotherapy: understanding the characteristics of tumor-infiltrating immune cells and their therapeutic implications. Cell Mol Immunol. 2020 Aug;17(8):807-21.

17 Yi M, Jiao D, Xu H, Liu Q, Zhao W, Han X, et al. Biomarkers for predicting efficacy of PD-1/PD-L1 inhibitors. Mol Cancer. 2018 Aug 23;17(1):129.

18 Nywening TM, Wang-Gillam A, Sanford DE, Belt BA, Panni RZ, Cusworth BM, et al. Targeting tumour-associated macrophages with CCR2 inhibition in combination with FOLFIRINOX in patients with borderline resectable and locally advanced pancreatic cancer: a single-centre, open-label, dose-finding, nonrandomised, phase $1 \mathrm{~b}$ trial. Lancet Oncol. 2016 May; 17(5):651-62.

19 Cannarile MA, Weisser M, Jacob W, Jegg AM, Ries $\mathrm{CH}$, Rüttinger D. Colony-stimulating factor 1 receptor (CSF1R) inhibitors in cancer therapy. J Immunother Cancer. 2017 Jul 18; 5(1):53.

20 Galli SJ, Tsai M. IgE and mast cells in allergic disease. Nat Med. 2012 May;18(5):693-704.

21 Katsoulis-Dimitriou K, Kotrba J, Voss M, Dudeck J, Dudeck A. Mast cell functions linking innate sensing to adaptive immunity. Cells. 2020 Nov;9(12):2538.

22 Varricchi G, Galdiero MR, Loffredo S, Marone G, Iannone R, Marone G, et al. Are mast cells MASTers in cancer? Front Immunol. 2017 Apr;8:424.

23 Melillo RM, Guarino V, Avilla E, Galdiero MR, Liotti F, Prevete N, et al. Mast cells have a protumorigenic role in human thyroid cancer. Oncogene. 2010 Nov;29(47):6203-15.

24 Rabenhorst A, Schlaak M, Heukamp LC, Förster A, Theurich S, von Bergwelt-Baildon $\mathrm{M}$, et al. Mast cells play a protumorigenic role in primary cutaneous lymphoma. Blood. 2012 Sep;120(10):2042-54.

25 Dabiri S, Huntsman D, Makretsov N, Cheang M, Gilks B, Bajdik C, et al. The presence of stromal mast cells identifies a subset of invasive breast cancers with a favorable prognosis. Mod Pathol. 2004 Jun;17(6):690-5.
26 Rajput AB, Turbin DA, Cheang MC, Voduc DK, Leung S, Gelmon KA, et al. Stromal mast cells in invasive breast cancer are a marker of favourable prognosis: a study of 4,444 cases. Breast Cancer Res Treat. 2008 Jan; 107(2): 249-57.

27 Fleischmann A, Schlomm T, Köllermann J, Sekulic N, Huland H, Mirlacher M, et al. Immunological microenvironment in prostate cancer: high mast cell densities are associated with favorable tumor characteristics and good prognosis. Prostate. 2009 Jun;69(9):976-81.

28 Soucek L, Buggy JJ, Kortlever R, Adimoolam S, Monclús HA, Allende MT, et al. Modeling pharmacological inhibition of mast cell degranulation as a therapy for insulinoma. Neoplasia. 2011 Nov;13(11):1093-100.

29 Soucek L, Lawlor ER, Soto D, Shchors K, Swigart LB, Evan GI. Mast cells are required for angiogenesis and macroscopic expansion of Myc-induced pancreatic islet tumors. Nat Med. 2007 Oct;13(10):1211-8.

30 Zong L, Mo S, Yu S, Zhou Y, Zhang M, Chen $J$, et al. Expression of the immune checkpoint VISTA in breast cancer. Cancer Immunol Immunother. 2020 Aug;69(8):1437-46.

31 Yang J, Zong L, Wang J, Wan X, Feng F, Xiang Y. Epithelioid trophoblastic tumors: treatments, outcomes, and potential therapeutic targets. J Cancer. 2019 Jan;10(1):11-9.

32 Zong L, Zhang M, Wang W, Wan X, Yang J, Xiang Y. PD-L1, B7-H3 and VISTA are highly expressed in gestational trophoblastic neoplasia. Histopathology. 2019 Sep;75(3):421-30.

33 Henderson WR, Chi EY, Jong EC, Klebanoff SJ. Mast cell-mediated tumor-cell cytotoxicity. Role of the peroxidase system. J Exp Med. 1981 Mar;153(3):520-33.

34 Swindle EJ, Metcalfe DD, Coleman JW. Rodent and human mast cells produce functionally significant intracellular reactive oxygen species but not nitric oxide. J Biol Chem. 2004 Nov;279(47):48751-9.

35 Nakae S, Suto H, Iikura M, Kakurai M, Sedgwick JD, Tsai M, et al. Mast cells enhance T cell activation: importance of mast cell costimulatory molecules and secreted TNF. J Immunol. $2006 \mathrm{Feb}$;176(4):2238-48.

36 Nakae S, Suto H, Kakurai M, Sedgwick JD, Tsai M, Galli SJ. Mast cells enhance T cell activation: importance of mast cell-derived TNF. Proc Natl Acad Sci U S A. 2005 May; 102(18):6467-72.

37 Stelekati E, Bahri R, D’Orlando O, Orinska Z, Mittrücker HW, Langenhaun R, et al. Mast cell-mediated antigen presentation regulates $\mathrm{CD} 8+\mathrm{T}$ cell effector functions. Immunity. 2009 Oct;31(4):665-76.

38 Kashiwakura J, Yokoi H, Saito H, Okayama Y. $\mathrm{T}$ cell proliferation by direct cross-talk between OX40 ligand on human mast cells and OX40 on human T cells: comparison of gene expression profiles between human tonsillar and lung-cultured mast cells. J Immunol. 2004 Oct;173(8):5247-57. 
39 McLachlan JB, Hart JP, Pizzo SV, Shelburne CP, Staats HF, Gunn MD, et al. Mast cell-derived tumor necrosis factor induces hypertrophy of draining lymph nodes during infection. Nat Immunol. 2003 Dec;4(12):1199205.

40 Malaviya R, Ikeda T, Ross E, Abraham SN. Mast cell modulation of neutrophil influx and bacterial clearance at sites of infection through TNF-alpha. Nature. 1996 May;381(6577):7780.
41 De Filippo K, Dudeck A, Hasenberg M, Nye E, van Rooijen N, Hartmann K, et al. Mast cell and macrophage chemokines CXCL1/CXCL2 control the early stage of neutrophil recruitment during tissue inflammation. Blood. 2013 Jun;121(24):4930-7.
42 Milione M, Miceli R, Barretta F, Pellegrinelli A, Spaggiari P, Tagliabue G, et al. Microenvironment and tumor inflammatory features improve prognostic prediction in gastro-entero-pancreatic neuroendocrine neoplasms. J Pathol Clin Res. 2019 Oct;5(4):217-26.

43 Kawasaki K, Toshimitsu K, Matano M, Fujita M, Fujii M, Togasaki K, et al. An organoid biobank of neuroendocrine neoplasms enables genotype-phenotype mapping. Cell. 2020 Nov;183(5):1420-35. 